Case report

\title{
A rare cause of myocardial infarction: Vegetation embolism
}

\author{
Nermin Bayar *, Görkem Kuş, Selçuk Küçükseymen, Erkan Köklü, Şakir Arslan \\ Antalya Education and Research Hospital, Cardiology Department, Antalya, Turkey
}

\section{A R T I C L E I N F O}

\section{Article history:}

Received 12 June 2016

Received in revised form 1 August 2016

Accepted 2 August 2016

Available online 10 August 2016

\section{Keywords:}

Infective endocarditis

Vegetation

Myocardial infarction

\begin{abstract}
A B S T R A C T
Coronary artery septic embolization resulting in cardioembolic myocardial infarction is a rare complication of infective endocarditis. Diagnosis requires a combination of high clinical suspicion, echocardiography, coronary angiography and cultures of peripheral blood and/or embolic material. Optimal therapy is unknown. We present a case of ST segment elevation myocardial infarction resulting from coronary artery septic embolization. (C) 2016 The Society of Cardiovascular Academy. Production and hosting by Elsevier B.V. All rights reserved. This is an open access article under the CC BY-NC-ND license (http://creativecommons.org/licenses/by-nc-nd/4.0/).
\end{abstract}

\section{Introduction}

Acute myocardial infarction (MI) due to intracoronary septic emboli is a rare complication of infective endocarditis (IE). Autopsy studies which investigate patients with IE suggest coronary embolism is more prevalent than surviving case reports would suggest. ${ }^{1}$ We present a case of ST segment elevation MI resulting from coronary artery septic embolization.

\section{Case report}

A 40-year-old woman presented to our emergency department with squeezing substernal chest pain more than $4 \mathrm{~h}$. In initial evaluation, systolic pressure was $110 / 70 \mathrm{mmHg}$ and pulse rate was 110 beats per minute. Physical examination revealed apical systolic murmur and crackles at the basal segment of the lungs. Patient's temperature was $36.7^{\circ} \mathrm{C}$. She had no known cardiac risk factors and had no history of cardiovascular disease. Her admission electrocardiogram (ECG) showed acute ST segment elevation in leads V3-V6 and D2-D3-AVF (Fig. 1). Acetylsalicylic acid $300 \mathrm{mg}$ and clopidogrel $600 \mathrm{mg}$ was given. After initial evaluation in the emergency department, the patient was taken to the catheter laboratory for primary percutaneous coronary intervention (PCI). Coronary angiography showed total occlusion of left anterior descending artery after the second diagonal branch. Right coronary artery and left circumflex artery was normal (Fig. 2). Unfractionated heparin (7500 U) was administered intravenously and PCI was planned. Despite balloon support, our guide wire failed to cross the lesion. The patient was

\footnotetext{
* Corresponding author at: Antalya Eğitim ve Araştırma Hastanesi, Kardiyoloji Kliniği, Muratpaşa, Antalya, Turkey.

E-mail address: dr.nermin@mynet.com (N. Bayar).

Peer review under responsibility of The Society of Cardiovascular Academy.
}

taken to the coronary care unit for thrombolytic therapy (TT). In the intensive care unit, the patient's detailed history was taken. We learned that she was being investigated for anemia, weight loss and history of fever at the hematology unit in the last four months. During this period, she was using antibiotics occasionally. The patient had no history of oral contraceptive use. Before TT, transthoracic echocardiography was performed and showed that rheumatic severe mitral regurgitation, mobile mass compatible with vegetation at the edge of the anterior leaflet of mitral valve, partial chordae rupture and moderate tricuspid regurgitation. Pulmonary artery systolic pressure was $90 \mathrm{mmHg}$. Left ventricular systolic function and cardiac chamber size was normal. For this reason, we did not give TT. Diuretic therapy and nitroglycerin infusion was begun. Blood culture samples were taken and then an infectious disease specialist recommended prophylactic intravenous antibiotic therapy (gentamicin $240 \mathrm{mg} /$ day, ampiciline $4 \mathrm{~g}$ /day). In laboratory tests, hemoglobin was $5.6 \mathrm{~g} / \mathrm{dl}$, white blood cell was $11.7 \times 10^{3}$ per $\mu \mathrm{L}$ and platelet was $319 \times 10^{3}$ per $\mu$ L. Lipid parameters, tests associated with connective tissue disease, liver and kidney function tests were normal but erythrocyte sedimentation rate was $74 \mathrm{~mm} / \mathrm{h}$, C-reactive protein was $92 \mathrm{mg} / \mathrm{dl}$ and troponins were elevated at $3.4 \mathrm{ng} / \mathrm{ml}$. Hemoglobin level increased to $9.1 \mathrm{~g} / \mathrm{dl}$ after two units of erythrocyte suspension. The next day after clinical stabilization, the patient's three-dimensional and transesophageal echocardiography (TEE) was performed. Severe mitral regurgitation, $11 \times 15 \mathrm{~mm}$-sized mobile mass compatible with vegetation on the edge of the anterior leaflet of mitral valve and partial rupture of chordae were observed (Fig. 3). There was no lesion suggestive of septic emboli in abdominal ultrasound and brain tomography. IE associated with underlying rheumatic mitral valve and ST elevation MI due to septic emboli was considered for the patient. The blood cultures did not reveal any microorganisms. After the ninth day, the patient had been stabilized with medical treatment. Mitral valve replacement and coronary artery bypass grafting was performed by the Department of Cardiovascular 


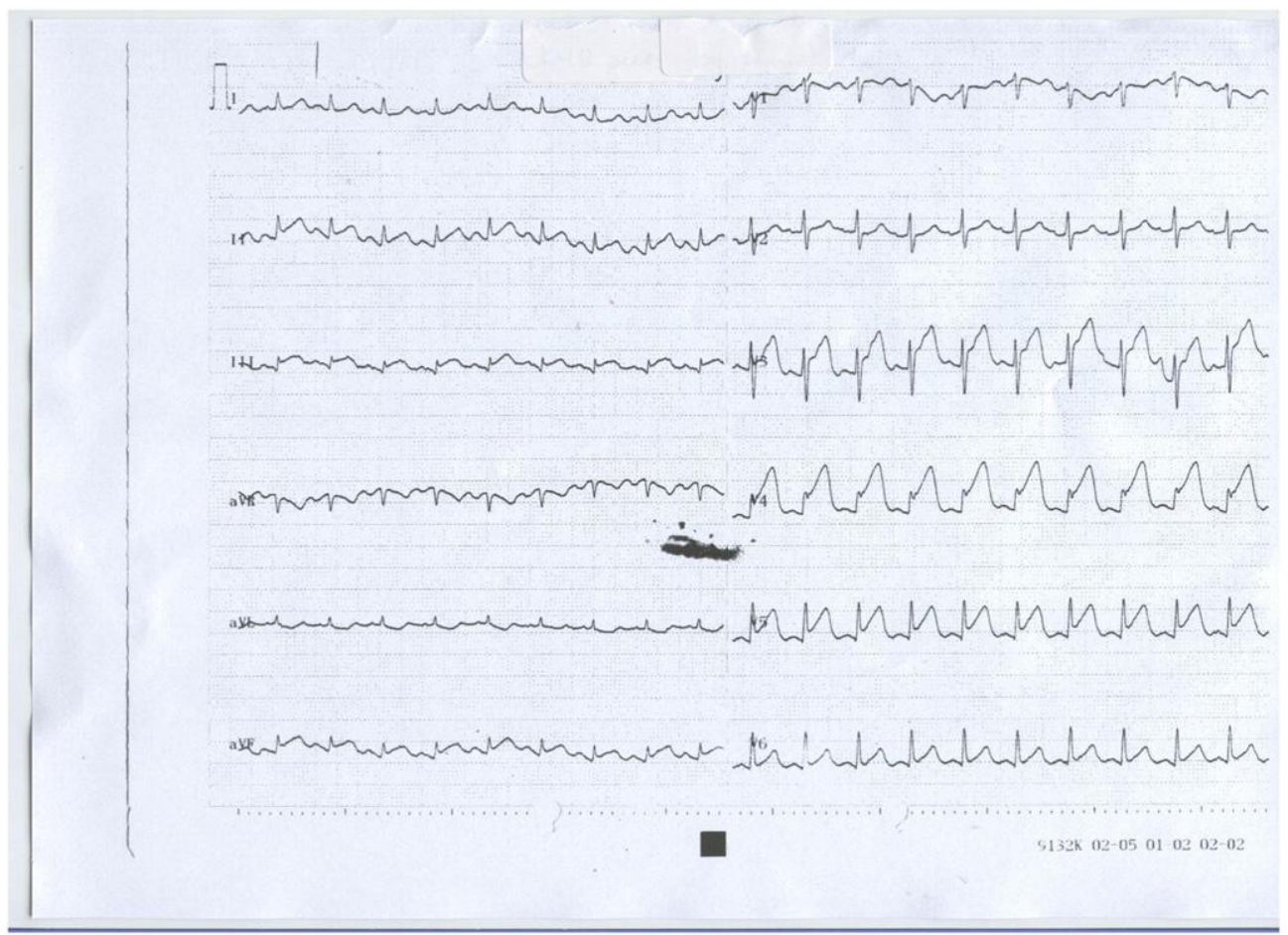

Fig. 1. Her admission electrocardiogram (ECG) showed acute ST segment elevation in leads V3-V6 and D2-D3-AVF.

Surgery. Vegetation that involved fibrin, neutrophils, plasma cells, lymphocytes and histiocytes were observed in the pathological examination of the resected mitral valve.

\section{Discussion}

MI associated with IE can occur due to septic embolization or compression of the coronary arteries by enlarging of aortic root abscess. ${ }^{2}$ Most embolization occurs on the left main coronary artery and left anterior descending artery due to favorable anatomy regarding the larger and downward course than the right coronary system which is angled significantly. ${ }^{3}$

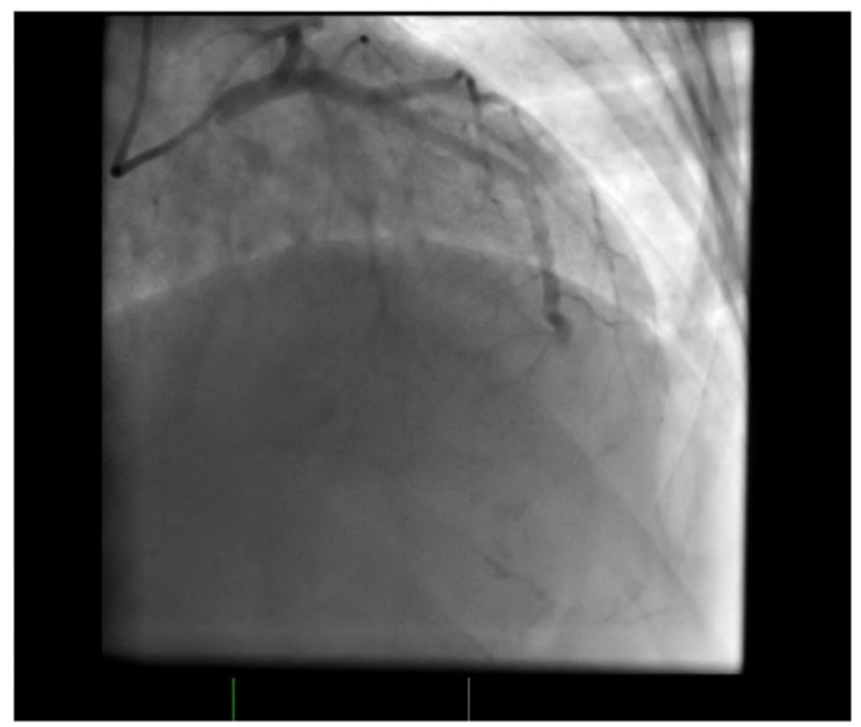

Fig. 2. Left coronary angiography showed total occlusion of the left anterior descending artery after the second diagonal artery.
On the left side of the endocarditis, risk of septic embolization to cerebral or peripheral organs is higher than coronary arteries. Septic embolization of coronary arteries is very rare but it may result in acute coronary syndrome. ${ }^{4}$ In some cases, high risk of embolization due to IE has been reported. Accordingly, the risk of complication is higher in the cases of IE that affected the anterior leaflet of mitral valve. Also, IE due to Staphylococcus aureus, Candida, HACEK organisms and abiotrophia are at higher risk for embolization. ${ }^{3,5,6}$ In our case, vegetation was observed in the anterior leaflet of the mitral valve. In spite of the circumflex and right coronary arteries being normal, observation of severe mitral regurgitation and chordal rupture was thought to be a result of local destruction caused by infection. In our case, the absence of positive blood cultures could be due to previous antibiotic usage.

Coronary embolism may cause ischemic chest pain, arrhythmias, valvular defects, pulmonary edema or sudden death. Severe valve regurgitation in the setting of endocarditis may be owing to destruction of valve or result of ischemia and infarction at the valvular apparatus. Anterolateral papillary muscle rupture as a result of embolic occlusion of the circumflex artery due to vegetation has been reported in the literature. ${ }^{7}$ In our case, bedside transthoracic echocardiography findings were consistent with IE. TEE was performed to evaluate the possible complications and mitral valve vegetations were shown clearly by three-dimensional echocardiography.

The optimal treatment of MI in the setting of IE is controversial. Anticoagulation is not recommended to prevent embolization. There are a small number of cases where successful TT in the setting of ST segment elevation MI was associated with IE. Despite this, TT is not recommended due to a high risk of intracranial bleeding related with therapy. ${ }^{8}$ Because lesions have a high risk of hemorrhage in cerebral vessels, such as mycotic aneurysms, which are more prevalent in IE. Also, septic conditions can increase the risk of intracranial hemorrhage leading to hemostasis disorders.

It seems safe to perform coronary angiography in the setting of IE. Abrupt occlusion of a coronary artery on angiography, despite the patency of other vessels and the absence of collaterals, should suggest the possibility of embolism. ${ }^{9}$ In our case, we did not think septic emboli 


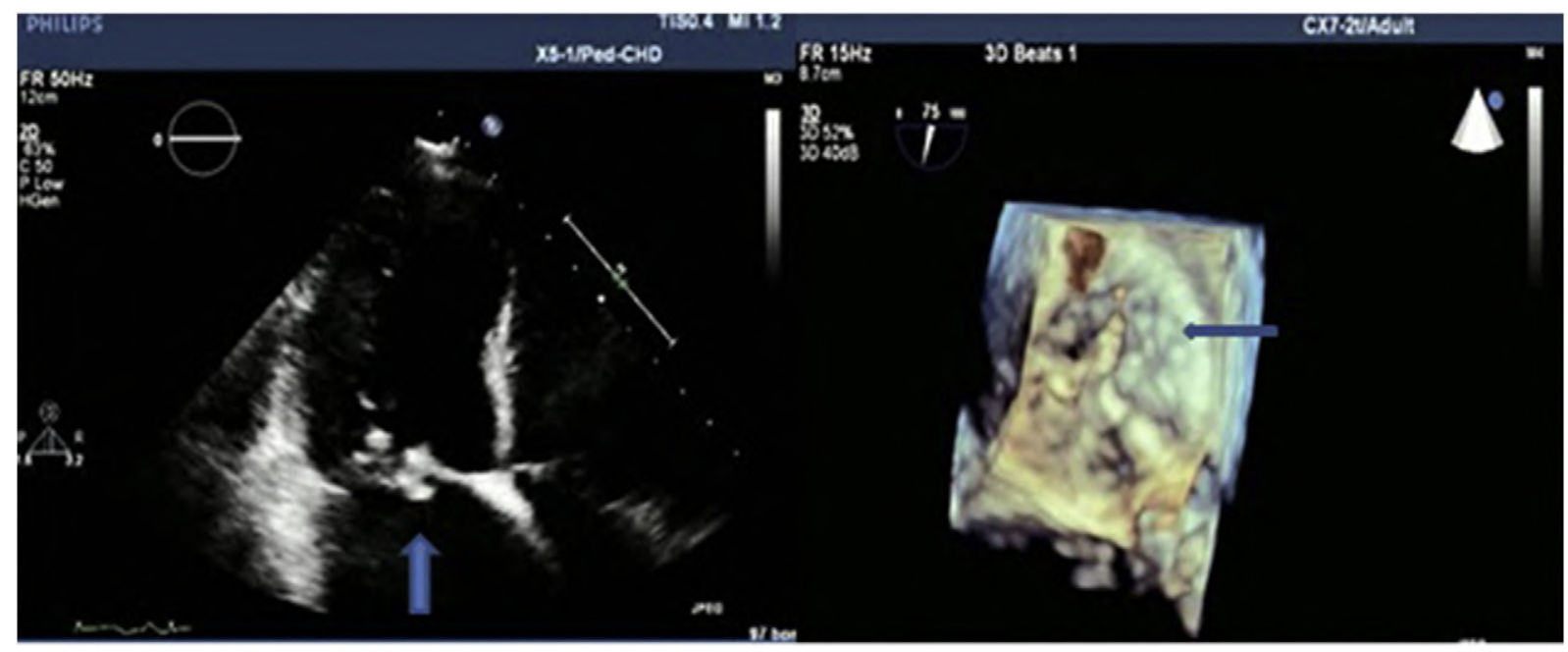

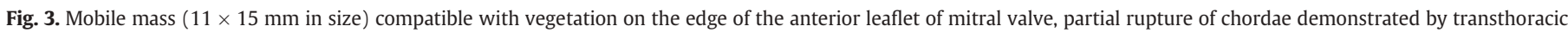
echocardiography and three-dimensional echocardiography.

in the first evaluation because of no known heart disease, fever or diagnosis of IE. The patient was transferred to the catheter laboratory for primary PCI from the emergency department without losing time. However, the echocardiography, which was performed before TT due to detection lesion compatible with emboli in coronary angiography, murmur on physical examination and the young age of the patient changed our treatment decision.

Primary percutaneous coronary intervention can be performed for emergency revascularization in patients with IE. However, there are conflicting results regarding safety and efficacy of $\mathrm{PCI}$ in these patients. Furthermore, $\mathrm{PCI}$ due to bacterial thrombotic lesion is more difficult than atherothrombotic lesions. If the coronary arterial wall is compliant as in younger patients, full expansion of the balloon may cause distal embolism. However, if the embolus is rigid, the lesion may not be cross with the guide wire or reocclusion of the vessel can occur after balloon angioplasty. In such patients, intracoronary stent placement is recommended to ensure vessel patency. Also, in these cases, there are some risks because of stent implantation in the infected area. Localized mycotic aneurysm can originate from the stent implanted area. ${ }^{10}$ If $\mathrm{PCI}$ cannot be performed, surgery and replacement of the infected valve should be performed to eliminate sources of embolism. Due to atherosclerotic changes on LAD coronary artery, in our first evaluation, we thought that myocardial infarction was associated with atherosclerotic plaque and therefore we planned to perform percutaneous coronary intervention. But, despite balloon support, our guide wire could not pass the lesion. In the foreground, we consider that infective endocarditis associated with myocardial infarction owing to the presence of mobile vegetation on TTE, the young age of the patient, the normal circumflex and right coronary arteries, the absence of risk factors for CAD and the clinical findings consistent with IE. However, it is possible that myocardial infarction was associated with atherosclerotic plaque rupture in our case.

In summary, the possibility of septic embolism should be considered in patients with IE who develop chest pain and ischemic ECG findings. In addition, the probability of septic emboli and IE should be considered in patients with ST elevation MI who have fever, murmur, and coronary angiographic findings compatible with embolism. Echocardiographic evaluation should be performed before thrombolytic therapy because MI may be the first presentation of IE.

\section{References}

1. Brunson JG. Coronary embolism in bacterial endocarditis. Am J Pathol 1953;20: 689-701.

2. Koike S, Takayama S, Furihata A, et al. Infective endocarditis causing acute myocardial infarction by compression of the proximal left coronary artery due to a mycotic aneurysm of the sinüs of Valsalva. Jpn Circ J 1991;55:1228-1232.

3. Kraus PA, Lipman J. Coronary embolism causing myocardial infarction. Intensive Care Med 1990;16:215-216.

4. Manzano MC, Vilacosta I, San Roman JA, et al. Acute coronary syndrome in infective endocarditis. Rev Esp Cardiol 2007;60:24-31.

5. Herzog CA, Henry TD, Zimmer SD. Bacterial endocarditis presenting as acute myocardial infarction: A cautionary note for the era of reperfusion. Am J Med 1991;90: 392-397.

6. Voss F, Bludau HB, Weretka S, et al. Mitral valve endocarditis: An uncommon cause of myocardial infarction. Z Kardiol 2003;92:686-688.

7. Najib MQ, Lee HR, DeValeria PA, et al. Anterolateral papillary muscle rupture: An unusual complication of septic coronary embolism. Eur J Echocardiogr 2011;12E10.

8. Hunter AJ, Girard DE. Thrombolytics in infectious endocarditis associated myocardial infarction. J Emerg Med 2001;4:401-406.

9. Roxas CJ, Weekes AJ. Acute myocardial infarction caused by coronary embolism from infective endocarditis. J Emerg Med 2011;40:509-514.

10. Ural E, Bildirici U, Kahraman G, et al. Coronary embolism complication aortic valve endocarditis: Treatment with successful coronary angioplasty. Int J Cardiol 2007;119:377-379. 